\title{
DOUBLING OF WORLD POPULATION UNLIKELY
}

\author{
Wolfgang Lutz \\ International Institute for Applied Systems Analysis \\ Laxenburg, Austria \\ Warren Sanderson \\ State University of New York at Stony Brook, New York, USA \\ Sergei Scherbov \\ University of Groningen, The Netherlands
}

RR-97-10

July 1997

Reprinted from Nature, Volume 387, Number 6635, June 19, 1997

International Institute for Applied Systems Analysis, Laxenburg, Austria Tel: +432236807 Fax: +43223673148 E-mail: publications@iiasa.ac.at 
Research Reports, which record research conducted at IIASA, are independently reviewed before publication. Views or opinions expressed herein do not necessarily represent those of the Institute, its National Member Organizations, or other organizations supporting the work.

Reprinted with permission from Nature, Volume 387, Number 6635, June 19, 1997. Copyright (C)1997 Macmillan Magazines Limited.

All rights reserved. No part of this publication may be reproduced or transmitted in any form or by any means, electronic or mechanical, including photocopy, recording, or any information storage or retrieval system, without permission in writing from the copyright holder. 


\section{Doubling of world population unlikely}

\section{Wolfgang Lutz ${ }^{\star}$, Warren Sanderson $\dagger$ \& Sergei Scherbov $\ddagger$}

* International Institute for Applied Systems Analysis (IIASA), Schlossplatz 1, A-2361 Laxenburg, Austria

$\dagger$ Department of Economics, State University of New York at Stony Brook, Stony Brook, New York 11794, USA

$\ddagger$ Population Research Centre, Faculty of Spatial Sciences, University of Groningen, PO Box 800, NL-9700 AV Groningen, The Netherlands

Most national and international agencies producing population projections avoid addressing explicitly the issue of uncertainty. Typically, they provide either a single projection or a set of low, medium and high variants ${ }^{1,2}$, and only very rarely do they give these projections a probabilistic interpretation. Probabilistic population projections have been developed for specific industrialized countries, mostly the United States, and are based largely on time-series analysis ${ }^{3}$. On a global level, time-series analysis is not applicable because there is a lack of appropriate data, and for conceptual reasons such as the structural discontinuity caused by the demographic transition ${ }^{4-6}$. Here we report on a new probabilistic approach that makes use of expert opinion on trends in fertility, mortality and migration, and on the 90 per cent uncertainty range of those trends in different parts of the world. We have used simulation techniques to derive probability distributions of population sizes and age structures for 13 regions of the world up to the year 2100 . Among other things, we find that there is a probability of two-thirds that the world's population will not double in the twenty-first century.

The probabilistic projections are based on distributions for fertility, mortality and migration in all regions, defined in terms of high or low values assumed to cover 90 per cent of all possible future outcomes. For today's high-fertility countries they are based on an assessment of their current standing in the process of demographic transition towards low fertility ${ }^{7}$, together with information about reproductive intentions ${ }^{8}$. These data show that even in sub-Saharan Africa the fertility transition has started, and that it is well advanced in most other developing regions. The high and low assumptions for the years 2030-2035 are total fertility rates (TFR, the number of children per woman) of 4.0 and 2.0 in Africa, central Asia and the Middle East, 3.0 and 1.7 in southern Asia, Pacific Asia and Latin America and 3.0 and 1.5 in Central East Asia (mostly China).

For today's industrialized countries the assumptions are based on a broad survey of possible future societal changes'. The United

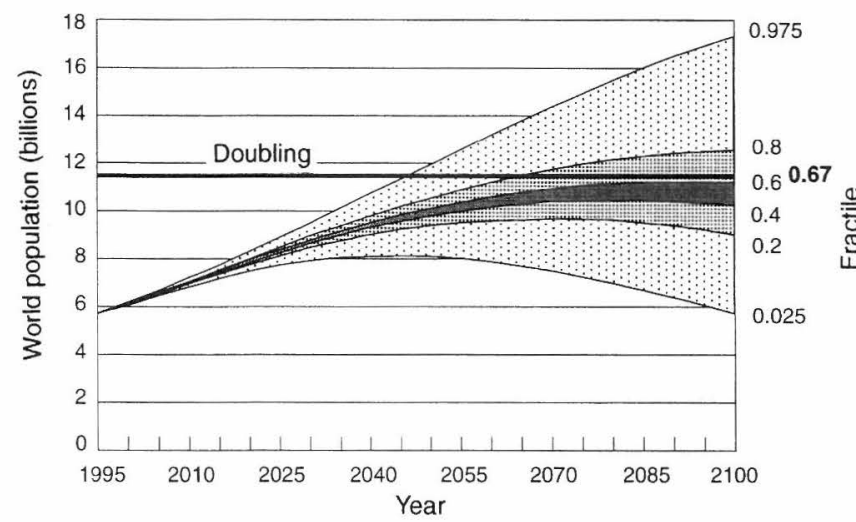

Figure 1 Fractiles of the probability distribution of the future size of the world population.
Nations and other institutions have assumed that fertility will eventually recover to replacement level (TFR slightly above 2.0), but there is little support for this view ${ }^{10,11}$. Accordingly, TFR values of 2.1 and 1.3 for Europe and the Pacific members of the Organization for Economic Cooperation and Development (OECD countries) and 2.3 and 1.4 for North America have been assumed for 2030-2035.

Assumptions for mortality were set in terms of increase in life expectancy at birth per decade. Contrary to earlier beliefs, there now is a considerable degree of uncertainty about the future course of mortality. In the industrialized countries this stems from the scientific dispute of whether we are already close to a biologically determined limit to life expectancy ${ }^{12,13}$. Accordingly, increases of 3.0 and 1.0 years have been assumed as the 90 per cent range. In the developing countries the uncertainty is more associated with future trends in AIDS ${ }^{14}$ and other infectious diseases and the development of health services ${ }^{15}$. For certain regions possible problems with food supply have also been considered ${ }^{16,17}$. Consequently in such cases the assumed range of mortality improvement is wide, for example +4.0 to -2.0 years per decade in sub-Saharan Africa.

Migration is most difficult to handle because of unreliable data and high volatility ${ }^{18}$. For this study a matrix of constant annual interregional migration flows was assumed with the 90 per cent ranges covering two million to zero migration gains in North America, and 1 million to zero in Western Europe.

The projections for 13 regions (see Table 1) show that population growth will probably be most rapid in the middle East, sub-Saharan Africa and North Africa, with a tripling of the population by 2050 and a quadrupling by 2100 likely. Despite this rapid growth, there will also be significant increases in the proportion above 60 years of age. In contrast, in Eastern Europe and the European part of the former Soviet Union, population will probably decrease over the coming decades. By 2050 the Pacific OECD countries and Western Europe are likely to experience little, if any, change in population size. This stagnation or shrinkage in population size in Europe and the Pacific OECD countries will be associated with significant ageing of the population, with the proportion above 60 likely to double from its current values. Even proportions well above 40 per cent are within the 95 per cent confidence interval. These could bring serious consequences for social security systems.

In North America, a younger age distribution, a larger inflow of migrants, and slightly higher fertility than in Europe is likely to result in a roughly 25 per cent increase in population by 2050 . Population ageing will occur, but will not be as dramatic as in Europe. Latin America is likely to have a doubling of its population and an increase in its proportion above age 60 to about 20 per cent. By 2050, Central East Asia (mostly China) is likely to grow by 37 per cent and experience an increase in the proportion over 60 from 9 per cent to 25 per cent. Southern Asia (essentially the Indian

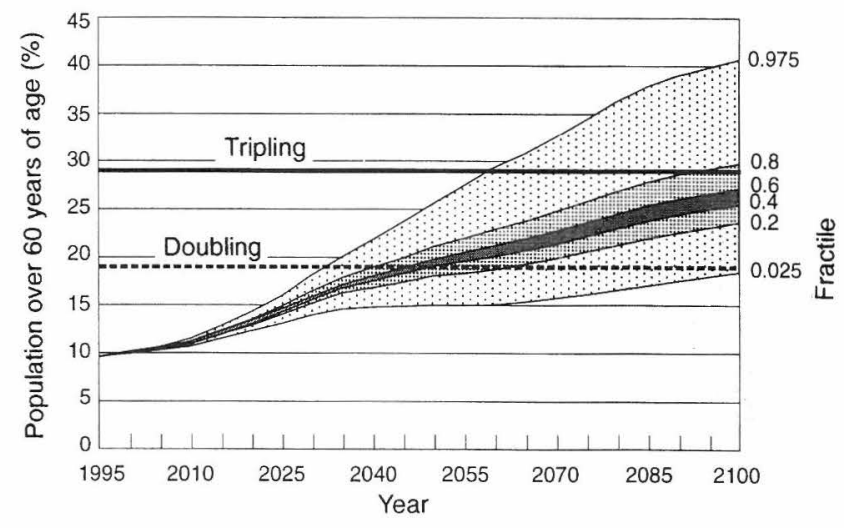

Figure 2 Fractiles of the probabiity distribution of the proportion of the world population above 60 years of age. 
Table 1 Result of probabilistic projections for 13 world regions

\begin{tabular}{|c|c|c|c|c|c|c|c|c|}
\hline \multirow[b]{3}{*}{ Region } & \multicolumn{4}{|c|}{ Total population (millions) } & \multicolumn{4}{|c|}{ Population above age 60 (in \%) } \\
\hline & \multirow[b]{2}{*}{1995} & \multicolumn{3}{|c|}{2050} & \multirow[b]{2}{*}{1995} & \multicolumn{3}{|c|}{2050} \\
\hline & & Median & $2.5 \% *$ & $97.5 \% *$ & & Median & $2.5 \% *$ & $97.5 \% *$ \\
\hline \multicolumn{9}{|l|}{ Africa } \\
\hline $\begin{array}{l}\text { North Africa } \\
\text { Sub-Saharan Africa }\end{array}$ & $\begin{array}{l}162 \\
558\end{array}$ & $\begin{array}{r}439 \\
1,605\end{array}$ & $\begin{array}{r}309 \\
1,085\end{array}$ & $\begin{array}{r}583 \\
2,316\end{array}$ & $\begin{array}{l}5.9 \\
4.7\end{array}$ & $\begin{array}{r}13.3 \\
9.2\end{array}$ & $\begin{array}{l}9.4 \\
6.9\end{array}$ & $\begin{array}{l}19.2 \\
12.8\end{array}$ \\
\hline \multicolumn{9}{|l|}{ East Asia } \\
\hline Pacific Asia & 447 & 796 & 579 & 1,047 & 6.8 & 19.4 & 14.4 & 26.5 \\
\hline Pacific OECD countries & 147 & 146 & 117 & 182 & 19.4 & 39.5 & 31.5 & 48.7 \\
\hline \multicolumn{9}{|l|}{ West Asia } \\
\hline Central Asia & 54 & 137 & 88 & 206 & 7.8 & 15.4 & 10.2 & 24.0 \\
\hline Middle East & 151 & 515 & 380 & 692 & 5.4 & 12.5 & 9.1 & 17.3 \\
\hline Southern Asia & 1,240 & 2,368 & 1,833 & 2,970 & 6.7 & 16.6 & 13.4 & 20.8 \\
\hline \multicolumn{9}{|l|}{ Europe } \\
\hline Eastern Europe & 122 & 110 & 86 & 141 & 16.7 & 34.0 & 26.7 & 43.4 \\
\hline Western Europe & 447 & 471 & 370 & 584 & 18.6 & 35.0 & 27.5 & 43.9 \\
\hline Latin America & 477 & 925 & 707 & 1,177 & 7.6 & 20.4 & 15.8 & 26.4 \\
\hline North America & 297 & 403 & 303 & 534 & 16.4 & 30.2 & 24.0 & 38.6 \\
\hline
\end{tabular}

Fertility, mortality and migration are assumed to be independent.

* Columns labelled $2.5 \%$ and $97.5 \%$ provide data on the lower and upper bounds, respectively, of the 95 per cent confidence interval.

subcontinent), which still has relatively high fertility and a young population, will probably double its population by 2050 and will be the world's most populous region.

The global results for population size are presented in Fig. 1; those for the proportion above 60 years of age are shown in Fig. 2. The median path of world population growth will increase from 5.8 billion today to 7.9 billion in 2020 and 10.0 billion in 2050. It will reach a peak around 2070-2080, and then begin a slow decline. In 2020 the range of uncertainty of this projection will be rather narrow (with the 95 per cent confidence interval between 7.5 billion and 8.3 billion) because many of the people who will be alive at that date have already been born. By 2050, the 95 per cent confidence interval will widen to between 8.1 billion and 11.9 billion, but the most likely 60 per cent (medium and dark shaded area in Fig. 1) still covers a range of less than one billion. After 2050 the size of the 95 per cent confidence interval will increase substantially, with the 60 per cent confidence interval showing a much smaller rise. The proportion of the world's population above age 60 is likely to increase from 9.5 per cent today to 20 per cent in 2050 to 27 per cent by 2100 . A strong increase in the proportion of elderly people is virtually certain, with the low end of the 95 per cent confidence interval showing almost a doubling of today's level.

These probabilistic projections lead us to believe that the focus of public, political and scientific concern will continue to shift from global population growth to population ageing.

\section{Methods}

The probabilistic population projections are based on the multistate cohortcomponent model of population projections, which applies assumed agespecific fertility, mortality and migration rates to the age and sex distribution of the starting population along cohort lines ${ }^{19,20}$. A group of demographers have analysed trends in fertility, mortality and migration in different parts of the world $^{21}$. Their discussions produced a consensus about ranges in 2030-2035 that they thought would cover 90 per cent of all future paths of TFR, life expectancy at birth, and the interregional migration matrix ${ }^{22}$. Because the resulting distributions of assumed values turned out to be symmetric, normal distributions were fitted to those ranges. For each of the three variables, a single draw from a standard normal distribution determined its relative position within its range of future values at selected dates. The values at intermediate dates were determined by piece-wise linear interpolation. This method has been labelled a random scenario approach to population projection ${ }^{23}$.
Experiments with less autocorrelated paths for each variable produced very similar means and medians and minor differences in variances ${ }^{24}$.

Beyond 2030-2035, fertility was assumed to reach an average level of between 1.7 and 2.1 children per woman by 2080 , with the specific value depending on population density in 2030 (the high the density, the lower the fertility). The 90 per cent range around that value was set at 1.0 children. The range for life-expectancy increases after 2030-2035 was set to $0-2.0$ years per decade. Smooth transitions of assumed future life expectancies at birth into age-specific mortality rates were performed by transforming baseline mortality patterns with the help of relational models ${ }^{25}$. Because separate baseline data were needed for males and females in each region, 26 patterns were used. Agespecific fertility rates were derived from the total fertility rates by using a fixed relative age profile of fertility. We used a fixed relative age profile for migrants to determine age-specific migration rates. The projections were performed in fiveyear steps on populations in five-year age groups.

An unusual feature of this global projection is the explicit consideration of possible correlations in fertility and mortality between and within regions. Four sets of 1,000 simulations were produced, resulting from a cross-classification of perfectly correlated/uncorrelated fertility and mortality trends across regions and within regions. The regional results presented in Table 1 are from the set with uncorrelated trends. The global results are based on the merged distribution of all four sets of simulations, which make up 4,000 projections in total.

Received 30 December 1996; accepted 17 April 1997.

1. United Nations World Population Prospects: The 1994 Revision (United Nations, New York, 1995). 2. United Nations Long-Range World Population Projections: Two Centuries of Population Growth 19502150 (United Nations, New York, 1992).

3. Lee, R. D. Stochastic demographic forecasting. Int. J. Forecast. 8, 315-327 (1992).

4. Nordhaus, W. Managing the Global Commons (MIT Press, Cambridge, MA, 1994)

. Alho, J. Scenarios, uncertainty, and conditional forecasts of the world population. J. R. Statist. Soc. A 160, Part 1,71-85 (1997)

6. Lutz, W., Goldstein, J. R. \& Prinz, C. in The Future Population of the World. What Can We Assume Today? (ed. Lutz, W.) 14-44 (Earthscan, London, 1996).

7. Cleland, J. in The Future Population of the World. What Can We Assume Today? (ed. Lutz, W.) 47-72 (Earthscan, London, 1996).

8. Westoff, C. F. in The Future Population of the World. What Can We Assume Today? (ed. Lutz, W.) 73-87 (Earthscan, London, 1996)

9. Lutz, W. in The Future Population of the World. What Can We Assume Today? (ed. Lutz, W.) 253-277 (Earthscan, London, 1996).

10. Keyfitz, N. in Future Demographic Trends in Europe and North America. What Can We Assume Today? (ed. Lutz, W.) 235-246 (Academic, London, 1991).

11. Westoff, C. F. in Future Demographic Trends in Europe and North America. What Can We Assume Today? (ed. Lutz, W.) 227-233 (Academic, London, 1991).

12. Vaupel, J. W. \& Lundström, H. in The Future Population of the World. What Can We Assume Today? (ed. Lutz, W.) 278-295 (Earthscan, London, 1996).

3. Manton, K. G. in Future Demographic Trends in Europe and North America. What Can We Assume Today? (ed. Lutz, W.) 97-115 (Academic, London, 1991). 
14. Bongaarts, J. in The Future Population of the World. What Can We Assume Today? (ed. Lutz, W.) 170195 (Earthscan, London, 1996).

15. Garenne, M. in The Future Population of the World. What Can We Assume Today? (ed. Lutz, W.) 149169 (Earthscan, London, 1996).

16. Heilig, G. K. in The Future Population of the World. What Can We Assume Today? (ed. Lutz, W.) 196249 (Earthscan, London, 1996).

17. Cohen, J. E. How Many People Can the Earth Support? (Norton, New York, 1995),

18. Zlotnik, H. in The Future Population of the World. What Can We Assume Today? (ed. Lutz, W.) 299-335 (Earthscan, London, 1996)

19. Keyfitz, N. Applied Mathematical Demography (John Wiley, New York, 1977).

20. Rogers, A. Introduction to Multiregional Mathematical Demography (John Wiley, New York, 1975).

21. Lutz, W. (ed.) The Future Population of the World. What Can We Assume Today? Revised Edition. (Earthscan, London, 1996)

22. Lutz, W. Scenario Analysis in Population Projection (Working Paper WP-95-57, International Institute for Applied Systems Analysis, Laxenburg, Austria, 1995).

23. Lee, R. D. Probabilistic approaches to population forecasting, in Rethinking Population Projections (eds Lutz, W. \& Vaupel, J. W.) (International Institute for Applied Systems Analysis, Laxenburg, Austria) (submitted 1996)

24. Lutz, W. \& Scherbov, S. Sensitivity Analysis of Expert-Based Probabilisitc Population Projections in the Case of Asutria (Working Paper, International Institute for Applied Systems Analysis, Laxenburg, Austria, 1997).

25. Brass, W. in Biological Aspects of Demography (ed. Brass, W.) 69-110 (Taylor and Francis, London, 1971).

Acknowledgements. This work has been conducted at IIASA (International Institute for Applied Systems Analysis)

Correspondence and requests for materials should be addressed to W.L. (e-mail: lutz@iiasa. ac.at). 
